\title{
Resistance of Gram-negative Bacteria to Purified Bactericidal Leukocyte Proteins
}

\author{
RELATION TO BINDING AND BACTERIAL LIPOPOLYSACCHARIDE \\ STRUCTURE
}

\author{
Jerrold Weiss, Susan Beckerdite-Quagliata, and Peter Elsbach, \\ Department of Medicine, New York University School of Medicine, \\ New York 10016
}

\begin{abstract}
A B S T R A C T The sensitivity or resistance of gramnegative bacteria to antibacterial systems appears to be related to the length of the saccharide chain of the bacterial envelope lipopolysaccharides (LPS). To explore this relationship further, we made use of two bactericidal, membrane-active cationic proteins, recently purified to near homogeneity, one from human and one from rabbit polymorphonuclear leukocytes (PMN). We have studied the effects of these two closely similar proteins on strains of Salmonella typhimurium and Escherichia coli, each separate strain differing in the saccharide chain length of its outer membrane LPS. Binding of these proteins to the bacterial outer membrane is required for killing, and is accompanied by an almost immediate increase in outer membrane permeability to normally impermeant actinomycin D. Sensitivity to the bactericidal and permeability-increasing activities of the human and rabbit proteins increases with decreasing LPS-saccharide chain length (chemotype: $\left[\mathrm{S}<\mathrm{Ra}<\mathrm{Rb}_{3}<\mathrm{Rc}_{\mathrm{c}}<\mathrm{Rd}_{1}\right]$ ). S. typhimurium G-30 and E. coli J5, mutant strains lacking UDP-galactose-4-epimerase, synthesize incomplete LPS (chemotype Rc) when grown without galactose, and are then as sensitive to both PMN proteins as the $S$. typhimurium strains $395 \mathrm{R} 10\left(\mathrm{Rd}_{1}\right)$ and $\mathrm{R} 5\left(\mathrm{Rb}_{3}\right)$. However, when these mutants are grown with galactose, they synthesize complete LPS (chemotype $S$ ) and exhibit nearly the same relative insensitivity as the smooth strains $S$. typhimurium 395 MS and E. coli 0111:B4.
\end{abstract}

The differences among strains in sensitivity to the effects of the proteins on bacterial viability and permeability correspond to differences in bacterial binding of these PMN proteins. Thus, at protein con-

\footnotetext{
Received for publication 1 August 1979.
}

centrations that produce maximal antibacterial activity toward the rough bacteria, but little or no activity toward the smooth strains, rough bacteria bind from 3- to 10-fold more protein (S. typhimurium 395 R10; S. typhimurium G-30, and E. coli J5 [grown without galactose]) than do the smooth bacteria ( $S$. typhimurium 395 MS; E. coli 0111:B4; S. typhimurium G-30 and E. coli J5 [grown with galactose]). These findings suggest that bacterial sensitivity or resistance to these purified bactericidal PMN proteins is determined by the binding properties of the outer membrane, which in turn depends upon the LPS-saccharide chain length.

\section{INTRODUCTION}

We have recently purified, to near homogeneity, two very similar cationic, membrane-active proteins from human and rabbit polymorphonuclear leukocytes $(\mathrm{PMN})^{1}$ that are potently bactericidal toward several strains of the gram-negative bacterial species, Escherichia coli and Salmonella typhimurium $(1,2)$. Rapid killing of these bacteria is accompanied by subtle envelope alterations that appear restricted to the outer membrane. These alterations include an almost immediate, discrete increase in outer membrane permeability (1-4; unpublished observations). To produce these antibacterial effects, the bactericidal/permeability-increasing $(\mathrm{PI})$ proteins apparently must bind to the outer membrane of the gram-negative bacterial envelope (3-5).

The degree of effectiveness against gram-negative bacteria of many antibacterial systems, including

'Abbreviations used in this paper: ActD, actinomycin D; LPS, lipopolysaccharides; PI, permeability increasing; PMN, polymorphonuclear leukocytes. 
cellular and humoral host defenses and antibiotics, depends largely on the physicochemical properties of this outer membrane (6-10). These properties mainly appear determined by the length of the polysaccharide chain of the outer membrane lipopolysaccharides (LPS) (11-13). Smooth strains (containing long-chain LPS) are more resistant than rough strains (containing short-chain LPS) to host defenses in vivo (6) and to killing in vitro by intact PMN (7), crude and partially purified extracts of PMN (14-17) and serum (18).

None of these earlier studies was carried out with defined antibacterial substances. The availability of nearly pure and well-characterized leukocyte proteins $(1,2)$, with apparent antibacterial specificity for gram-negative bacteria, prompted us, therefore, to further examine the relationship between bacterial LPS structure and the sensitivity of $S$. typhimurium and $E$. coli to the action of these proteins.

We find that rough strains of $S$. typhimurium and E. coli, with short-chain LPS, avidly bind both proteins and are exquisitely sensitive to their antibacterial activity. In contrast, smooth strains, with long-chain LPS, show much less binding and a correspondingly reduced sensitivity, suggesting that the LPS-polysaccharide chain length determines bacterial sensitivity or resistance to these bactericidal P.MN proteins by affecting the binding properties of the bacterial outer membrane.

\section{METHODS}

\section{Bactericidal/PI proteins}

The bactericidal/PI proteins were isolated from human and rabbit PMN as previously described $(1,2)$. The protein fractions used in this study were at least $95-98 \%$ pure as determined by gel filtration and electrophoresis in three or more different buffer systems.

\section{Bacteria}

The smooth, mouse-virulent strain S. typhimurium MS 395 and rough mutants derived from it (R2, R5, and R10) were kindly donated by Dr. Olle Stendahl (Department of Medical Microbiology, University of Linköping, Sweden). S. typhimurium G-30 and E. coli J5, mutants that lack the enzyme UDP-galactose-4-epimerase, and $E$. coli 0111:B4 (smooth parent strain of J5) were gifts of Dr. Mary J. Osborn (Department of Microbiology, University of Connecticut Health Center, Farmington, Conn.) and Dr. Loretta Leive (Laboratory of Biochemical Pharmacology, National Institute of Arthritis, Metabolic, and Digestive Diseases, National Institutes of Health, Bethesda, Md.). E. coli S15 (a K12 strain) was donated by Professor S. Nojima, University of Tokyo, Japan.

The structure of the LPS of these bacterial strains is schematically shown in Fig. 1. S. typhimurium strains were grown in nutrient broth (pH 7.3) and $E$. coli strains in a triethanolamine-buffered (pH 7.75-7.9) minimal salts medium (22). Bacterial cultures grown overnight to stationary phase were transferred to fresh medium (diluted 1:10) and the subcultures were grown to mid-late logarithmic phase $\left(\sim 3-4 \mathrm{~h}\right.$ at $37^{\circ} \mathrm{C} ; 6-10 \times 10^{8}$ bacteria/ml $)$. Where indicated, the growth media of both overnight and subcultures were supplemented with $5 \mathrm{mM}$ D-galactose. Bacterial concentrations were determined by measuring absorbance at 550 $\mathrm{nm}$ with a Coleman junior spectrophotometer Coleman Systems, Irvine, Calif. The bacteria were sedimented by centrifugation at $6,000 \mathrm{~g}$ for $10 \mathrm{~min}$ and resuspended in sterile physiological saline to provide the desired concentration.

\section{Assays for bactericidal and PI activities}

Typical incubation mixtures contained from $5 \times 10^{6}$ to $5 \times 10^{7}$ bacteria in a total volume of $0.4 \mathrm{ml}$ of sterile physiological saline that also contained $10 \mu \mathrm{mol}$ Tris- $\mathrm{HCl}$ buffer (pH 7.0), $25 \mu \mathrm{l}$ of Hanks' solution (Hanks' balanced salt solution [without phenol red], Microbiological Associates, Inc., Bethesda, Md.), $250 \mu \mathrm{g}$ of vitamin-free casamino acid (Difco Laboratories, Detroit, Mich.) and the purified bactericidal/PI protein in the indicated amount. Incubations were carried out for $30 \mathrm{~min}$ at $37^{\circ} \mathrm{C}$.

Bactericidal activity. After $30 \mathrm{~min}$ incubation, 10- $\mu \mathrm{l}$ samples were taken from the incubation mixtures, serially diluted in sterile isotonic saline and plated on nutrient agar. Bacterial viability was measured as the number of colony forming units on the plates after incubation at $37^{\circ} \mathrm{C}$ overnight.

PI activity. An effect of the bactericidal/PI proteins on the envelope permeability of $S$. typhimurium and $E$. coli was measured by determining the susceptibility of these bacteria to actinomycin D (ActD). The use of ActD for assay

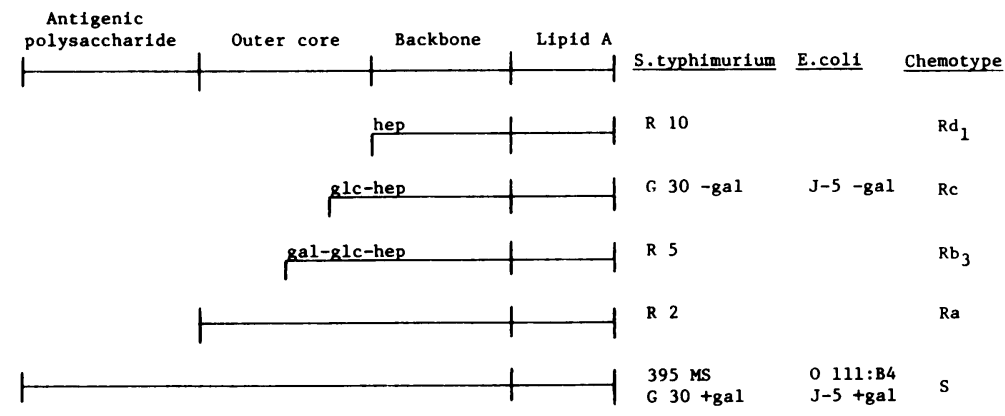

FIGURE 1 Schematic structures of the LPS of the various bacterial strains used in this study. The details of these structures have been previously described (19-21). 
of envelope permeability is based on the following observations:

(a) The envelope of gram-negative bacteria such as $S$. typhimurium and E. coli is normally impermeable to ActD (23). Hence, this antibiotic normally does not affect RNA and protein synthesis by these bacteria.

(b) Bactericidal concentrations of the bactericidal/PI proteins produce little or no inhibition of bacterial macromolecular synthesis for at least $2 \mathrm{~h}(1-3)$. Therefore, inhibition of RNA and protein synthesis by bacteria exposed to ActD and bactericidal/PI protein reflects an increase in envelope permeability to the antibiotic. Assays of PI activity were carried out in the incubation mixture described above by determining the bacterial incorporation of $\left[{ }^{14} \mathrm{C}\right]$ leucine $(0.063 \mu \mathrm{Ci} ; 0.13 \mathrm{mM}$ ) (New England Nuclear, Boston, Mass.) into cold trichloroacetic acid-precipitable material in the presence or absence of $12.5 \mu \mathrm{g}$ ActD (Merck Sharp and Dohme Div., Merck and Co., Inc. West Point, Pa.) $(5,24)$. Similar results were obtained using $\left[{ }^{14} \mathrm{C}\right]-$ uracil as precursor (24).

\section{Assay of binding of bactericidal/PI proteins to bacteria}

Because multiple attempts at radiolabeling the bactericidal/ PI proteins, without loss of bactericidal/PI activity, have so far remained unsuccessful, we have continued to rely on a biological assay for measuring bacterial binding of the proteins (5). The flow-sheet shown in scheme I (Fig. 2) serves to aid the reader in following the procedure.

After preincubation for $15 \mathrm{~min}$ at $37^{\circ} \mathrm{C}$ of a given bacterial strain $\left(6 \times 10^{8}\right.$ or $1.2 \times 10^{9}$ bacteria $)$ with $50 \mu \mathrm{g}$ of bactericidal/ PI protein in $0.75 \mathrm{ml}$ of the standard incubation mixture, the bacteria are pelleted by centrifugation at $6,000 \mathrm{~g}$ for 10 min at $4^{\circ} \mathrm{C}$. The amount of protein bound by the bacteria is estimated by measuring the reduction in bactericidal and PI activities recovered in the supernatant (I; Fig. 2) fraction. The bactericidal and PI activities of the purified human and

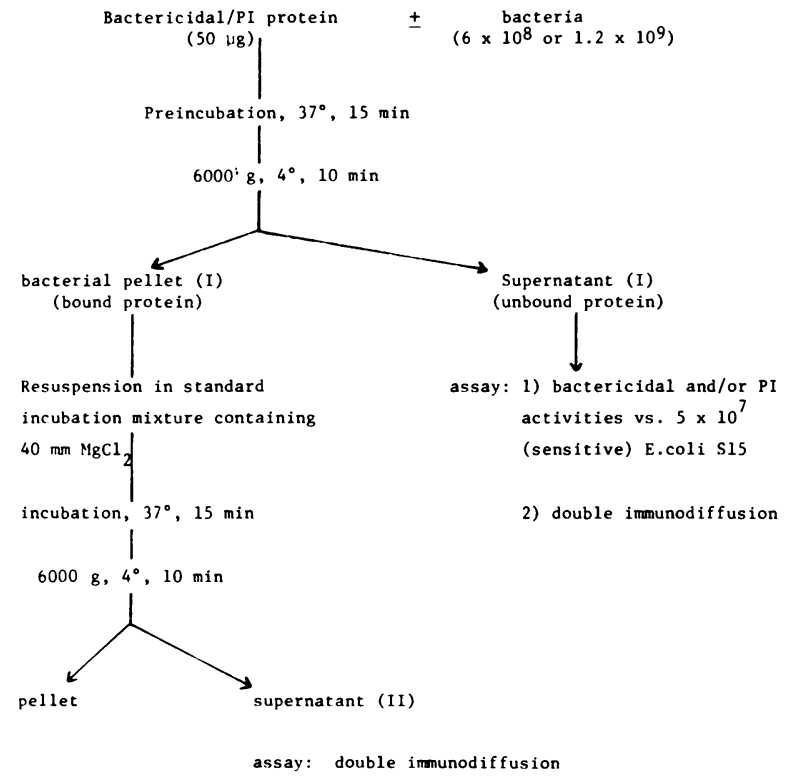

FIGURE 2 Flowsheet of steps in assay of binding of bactericidal/PI proteins to bacteria. rabbit leukocyte proteins are dose dependent $(1,2)$. Bound protein can therefore be quantitatively determined by comparing the bactericidal and PI activities of supernatant I obtained from preincubation mixtures with or without (control) bacteria. Each supernate is tested at various concentrations in the standard incubation medium against $5 \times 10^{7}$ (sensitive) E. coli S15. Under these experimental conditions, loss of activity from samples of protein preincubated alone, presumably because of adsorption to the glass tube, was $<20 \%$.

Binding of the human PMN protein to the bacteria was also demonstrated by the loss of immunochemically reactive protein from supernatant I fraction and its recovery in supernatant II fraction after release from the bacterial pellet I (see Fig. 2) upon resuspension in $0.75 \mathrm{ml}$ of the standard incubation mixture supplemented with $40 \mathrm{mM} \mathrm{MgCl}$ and incubation at $37^{\circ} \mathrm{C}$ for $15 \mathrm{~min}$. The supernatant $\mathrm{II}$ fraction was separated from the bacteria by centrifugation at $6,000 \mathrm{~g}$ for $10 \mathrm{~min}$ at $4^{\circ} \mathrm{C}$.

Immunochemical analysis of the two supernatant fractions was carried out by double immunodiffusion against rabbit anti-human bactericidal/PI protein-serum, obtained as previously described (1), in $1 \%$ agarose gels according to the method of Ouchterlony (25).

\section{RESULTS}

Influence of saccharide chain length of LPS on sensitivity of S. typhimurium 395 to bactericidal/PI proteins. Three strains of S. typhimurium 395, differing in the polysaccharide chain length of their outer membrane LPS (see Fig. 1), were compared for their sensitivity to the bactericidal and PI activities of the human and rabbit bactericidal/PI proteins. Fig. 3 shows that the sensitivity of these strains to the bactericidal activity of both proteins is inversely related to the LPS-saccharide chain length. Thus, R10 containing the shortest-chain LPS is most sensitive and MS, the smooth parent strain with complete LPS, is least sensitive. The bactericidal activities of the human and rabbit leukocyte proteins are nearly identical.

As with all other sensitive gram-negative bacterial strains previously examined $(1,2)$, killing of $S$. typhimurium $395 \mathrm{R} 10$ and R5, by either the human or rabbit bactericidal/PI protein, is accompanied by an almost immediate increase in outer membrane permeability to normally impermeant ActD (Fig. 3). Both bactericidal proteins exert their effect on bacterial viability without substantially inhibiting bacterial macromolecular synthesis $(1,2)$. Thus, incorporation of $\left[{ }^{14} \mathrm{C}\right]$ leucine into cold trichloroacetic acid-precipitable material by strains R10 and R5 is only slightly inhibited during incubation with bactericidal concentrations of either protein in the absence of ActD (Fig. 3). However, in the presence of ActD, both proteins cause a dose-dependent inhibition of bacterial protein synthesis that parallels their bactericidal action.

Neither the human nor the rabbit protein produces detectable killing of S. typhimurium 395 MS at the concentrations of protein and bacteria used in 


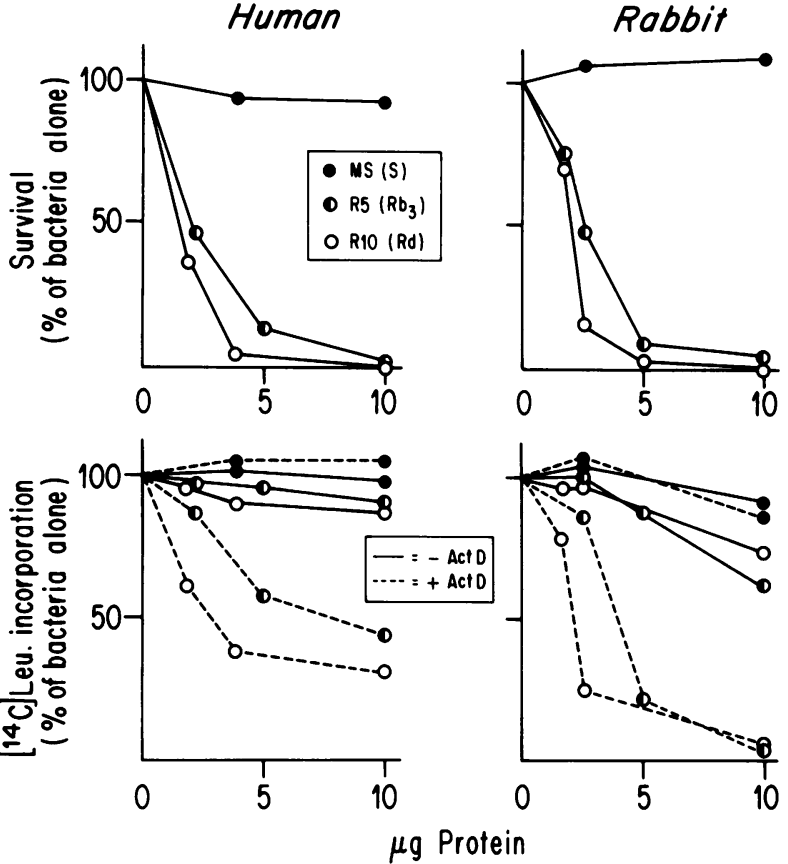

FIGURE 3 Effect of LPS structure on sensitivity of $S$. typhimurium 395 to human and rabbit PMN bactericidal/PI proteins. Of three strains of S. typhimurium 395 (MS [chemotype S], $; \mathbf{R}_{5}$ [chemotype Rb3], $\mathbf{O} ; \mathrm{R} 10$ [chemotype Rd], O), $5 \times 10^{7}$ bacteria were incubated for $30 \mathrm{~min}$ at $37^{\circ} \mathrm{C}$ with increasing concentrations of either human or rabbit bactericidal/PI protein (abscissa). The upper panels show bacterial viability expressed as percent (ordinate) of the number of colony forming units of a given bacterial strain incubated alone. The lower panels show effects on bacterial permeability, as determined by measuring bacterial incorporation of $\left[{ }^{14} \mathrm{C}\right]$ leucine $\left(\left[{ }^{14} \mathrm{C}\right]\right.$ leu $)$ into trichloroacetic acid-precipitable material in the absence $(-)$ and presence $(--)$ of ActD as described in Methods. Leucine incorporation is expressed as percent (ordinate) of incorporation by bacteria incubated alone $(>2,000 \mathrm{cpm} ; 1-2 \mathrm{nmol})$. The results represent the means of three closely similar experiments.

the experiments shown in Fig. 3. However, killing is readily apparent upon exposure of fewer bacteria (MS) to higher concentrations of the two proteins (Table I). Table I further shows that a fourth strain of S. typhimurium $395 \mathrm{R} 2$ (chemotype Ra), with an LPS polysaccharide chain length intermediate between that of MS and R5, exhibits a correspondingly intermediate sensitivity to the two proteins. These findings suggest that the resistance of strains of S. typhimurium 395 to the leukocyte bactericidal/PI proteins is related to the length of their LPS-polysaccharide chain. However, other differences in the envelope structure of these strains might also contribute to these differences in sensitivity.

UDP-galactose-4-epimeraseless mutants: sensitivity to bactericidal/PI proteins after growth with or without galactose. The influence of LPS-polysaccharide
TABLE I

Sensitivity of Salmonella typhimurium 395 to the Bactericidal Activity of Purified Bactericidal/PI Protein from Human or Rabbit PMN: Effect of Polysaccharide Chain Length of Outer Membrane LPS

\begin{tabular}{lcc}
\hline \multirow{2}{*}{ Strain } & \multicolumn{2}{c}{ Add bactericidal/PI protein. } \\
\cline { 2 - 3 } & Human & Rabbit \\
\hline & & $\mu g / m l$ \\
R10 $(\mathrm{Rd})$ & $1-2$ & $1-2$ \\
R5 $\left(\mathrm{Rb}_{3}\right)$ & $4-5$ & $3-4$ \\
R2 $(\mathrm{Ra})$ & $20-30$ & $6-9$ \\
MS & $>30$ & 30 \\
\hline
\end{tabular}

Bactericidal activity was determined as described in Methods. Results shown represent the amount of protein (micrograms per milliliter) required to produce $>90 \%$ killing of $10^{7}$ bacteria/ml and are the mean of at least three experiments.

chain length on gram-negative bacterial resistance to the bactericidal/PI proteins can be more specifically examined by using mutants of S. typhimurium (G-30) and $E$. coli (J5) that lack the enzyme UDP-galactose4 -epimerase. These mutants are conditionally defective in LPS biosynthesis, synthesizing galactose-deficient, incomplete LPS (chemotype Rc, see Fig. 1) when grown without added galactose. However, when grown in media supplemented with galactose, these bacteria produce complete LPS (chemotype S) that is indistinguishable from LPS of its smooth parent strain. In contrast to their differences in LPS structure, the bacteria grown with or without galactose manifest no detectable differences in outer membrane protein and phospholipid content $(26,27)$.

Figs. 4 and 5 show that the synthesis of complete LPS by S. typhimurium G-30 or E. coli J5 is accompanied by increased resistance to the human and rabbit bactericidal/PI proteins. Whereas $4-5 \mu \mathrm{g}$ of either the human or the rabbit protein produce maximal bactericidal and PI effects toward both mutant strains grown without galactose, $>10 \mu \mathrm{g}$ of either PMN protein is needed to produce similar effects on the mutant strains after their growth with galactose. Supplementation of growth media with concentrations of galactose as low as $0.25 \mathrm{mM}$ elicits this increase in resistance. In contrast, resuspension of the mutants in $20 \mathrm{mM}$ galactose just before incubation with human or rabbit leukocyte protein does not increase bacterial resistance. The resistance of $E$. coli J5 grown with galactose is practically identical to that of its smooth parent strain, E. coli 0111:B4.

The bactericidal and PI activities of the human and rabbit PMN proteins toward all S. typhimurium and $E$. coli strains that we have studied are remarkably similar. However, whereas these activities of the two proteins are nearly identical toward bacteria with short- 

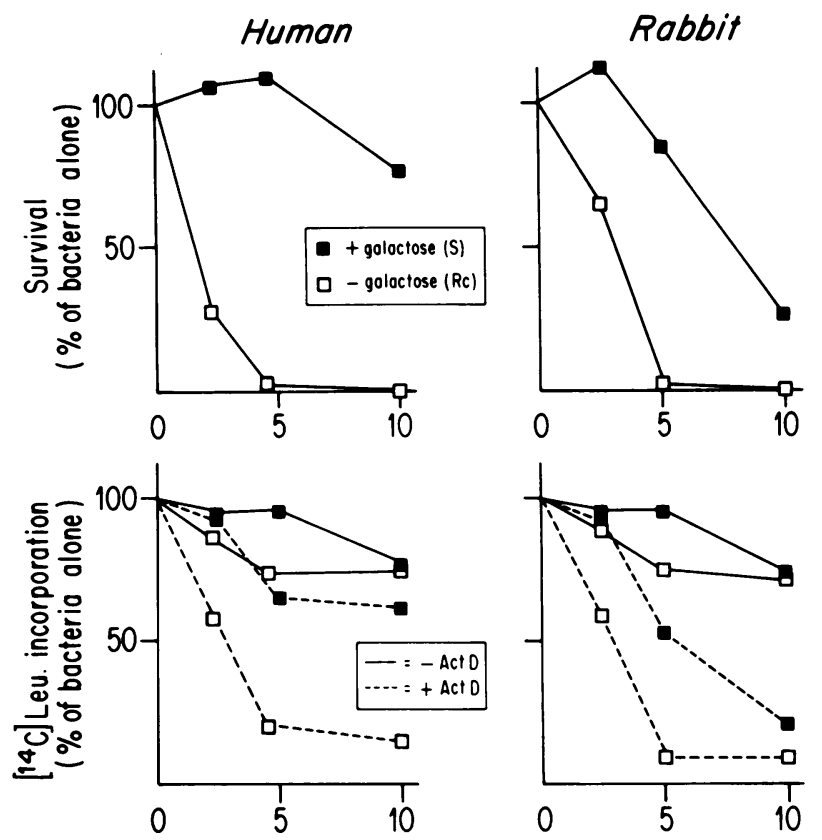

$\mu g$ Protein

FIGURE 4 Effect of LPS structure on sensitivity of S. typhimurium G-30 to human and rabbit P.MN bactericidal/PI proteins. Viability (upper panels) and permeability (lower panels) of S. typhimurium G-30 $\left(5 \times 10^{7}\right.$ bacteria) incubated with increasing concentrations of the human and rabbit proteins after bacterial growth in the presence $(\boldsymbol{\square})$ or absence ( $\square$ ) of $5 \mathrm{mM}$ D-galactose were determined as described in Methods and the legend to Fig. 3 . The results represent the mean of three closely similar experiments.

chain LPS, the rabbit protein is consistently slightly more active than the human protein toward bacteria with longer-chain LPS.

Binding of bactericidal/PI proteins to S. typhimurium and E. coli: effect of LPS-saccharide chain length. To produce their antibacterial effects, the bactericidal/PI proteins apparently must bind to the bacterial outer membrane $(3,5)$. Longer-chain LPS might enhance bacterial resistance by reducing the affinity of the outer membrane for the bactericidal/PI proteins. Therefore, we compared binding of the human and rabbit proteins to bacteria containing short or long chain LPS. As described in Methods, we have been compelled to measure binding indirectly: that is, as the loss of antibacterial (bactericidal and PI) activity from the soluble phase during incubation of the bactericidal/PI proteins with different bacterial strains.

Figs. 6-8 show that much less of the bactericidal and PI activities are recovered in the supernatant fraction after preincubation of either protein with rough bacterial strains than in the supernatant fraction after preincubation with smooth strains. This presumably reflects greater binding of the two proteins to bacteria with short-chain LPS. The extent of apparent protein
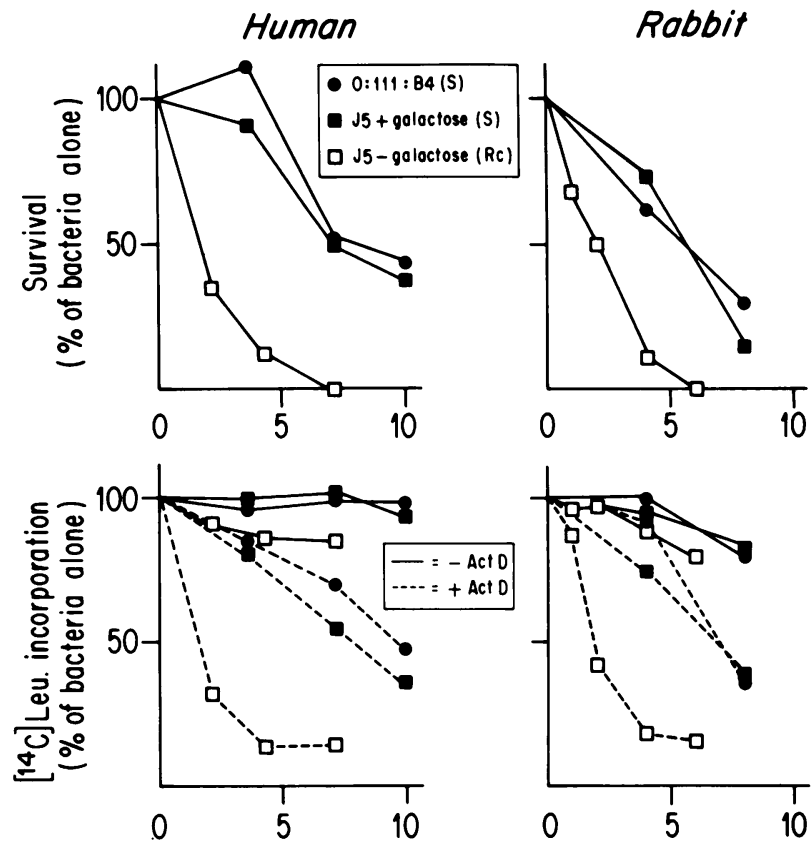

$\mu \mathrm{g}$ Protein

FIgURE 5 Effect of LPS structure on sensitivity of $E$. coli to human and rabbit bactericidal/PI proteins. Viability (upper panels) and permeability (lower panels) of $E$. coli 0111:B4 and of E. coli J5, grown in the presence ( $\square$ ) or absence ( $\square$ ) of $5 \mathrm{m.M}$ D-galactose and incubated with increasing concentrations of the human and rabbit proteins, were determined as described in Methods and the legend to Fig. 3. The results represent the mean of three closely similar experiments.

binding to bacteria with either short- or long-chain LPS depends on the number of bacteria present in the preincubation mixture (Figs. 6-8). We calculate from these experiments that during incubation of $4.5 \mu \mathrm{g}$ of either protein with $4 \times 10^{7}$ bacteria $\sim 3 \mu \mathrm{g}$ is bound to each of the rough bacterial strains, but only $0.3-1.1 \mu \mathrm{g}$ is bound to the smooth strains (Table II).

The extent of apparent binding of the bactericidal/PI proteins generally corresponds to their biological effects. Thus, the lower antibacterial potency of the bactericidal/PI proteins toward the smooth bacteria parallels their reduced binding. This correlation is most clearly illustrated by comparing the apparent binding and biological activity of either the human or the rabbit PMN protein toward the UDP-galactose4-epimeraseless mutants S. typhimurium G-30 and E. coli J5. When grown without galactose, these two mutants exhibit a similar sensitivity to that of the Rd mutant of S. typhimurium $395 \mathrm{R} 10$ and bind approximately the same amount of protein. However, after growth in the presence of galactose, both the binding and sensitivity of these two mutant strains become greatly reduced and indistinguishable from that of smooth strains (S. typhimurium 395 MS; E. coli 0111: 

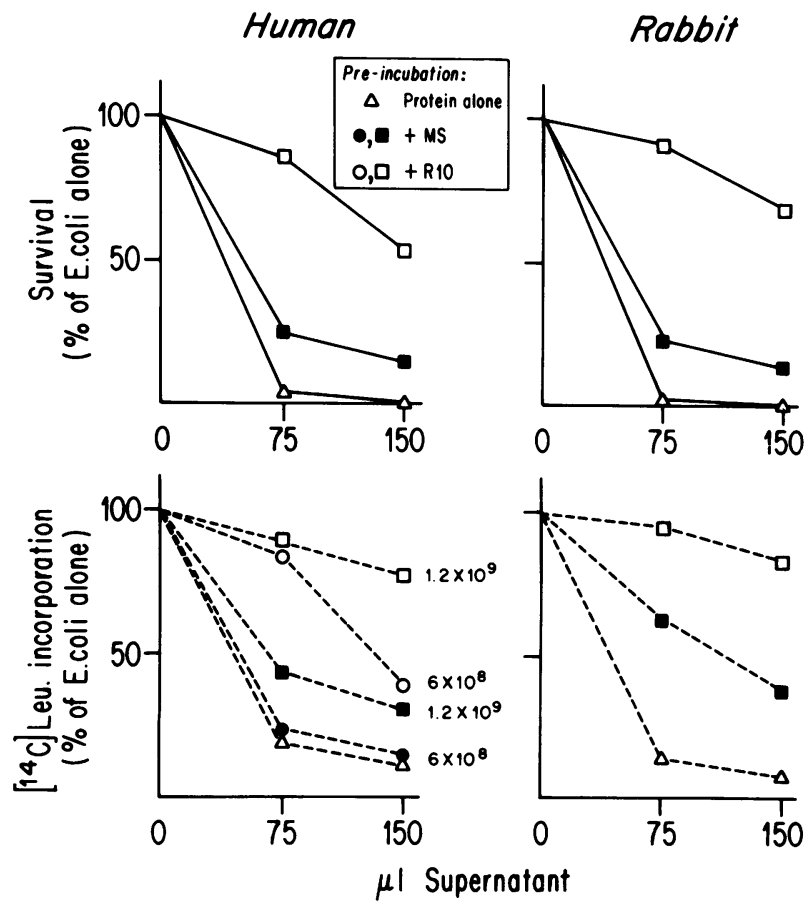

FIGURE 6 Binding of human and rabbit bactericidal/PI proteins to $S$. typhimurium 395: influence of LPS structure. Supernatant fractions were obtained as described in Methods after preincubation of $50 \mu \mathrm{g}$ of the human or the rabbit bactericidal/PI protein alone $(\Delta)$, or with $6 \times 10^{8}$ (circles), or with $1.2 \times 10^{9}$ (squares) S. typhimurium 395 (MS, closed symbols; R10, open symbols). These fractions were assayed for bactericidal and PI activities toward $5 \times 10^{7} \mathrm{E}$. coli S15 as described in Methods. For simpler presentation, only $\left[{ }^{14} \mathrm{C}\right]$ leucine $\left(\left[{ }^{14} \mathrm{C}\right] \mathrm{leu}\right)$ incorporation in the presence of ActD (- - ) is shown. The results represent the mean of two closely similar experiments carried out in duplicate.

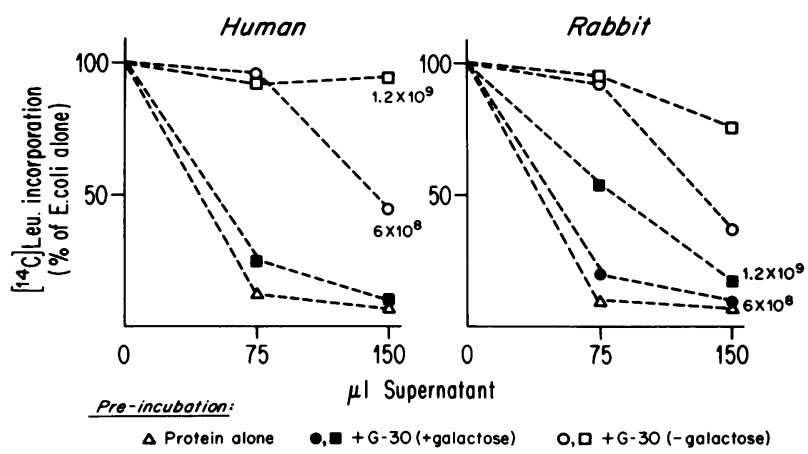

FIgURE 7 Binding of human and rabbit PMN bactericidal/PI proteins to $S$. typhimurium G-30: influence of LPS structure. PI activity of the supernatant fractions, recovered after preincubation of $50 \mu \mathrm{g}$ of the human or the rabbit bactericidal/ PI protein alone $(\triangle)$, or with $6 \times 10^{8}$ (circles), or with $1.2 \times 10^{9}$ (squares) S. typhimurium G-30 grown in the presence (closed symbols) or absence of galactose (open symbols) was determined as described in Methods and the legend to Fig. 6. The results represent the mean of two closely similar experiments carried out in duplicate.
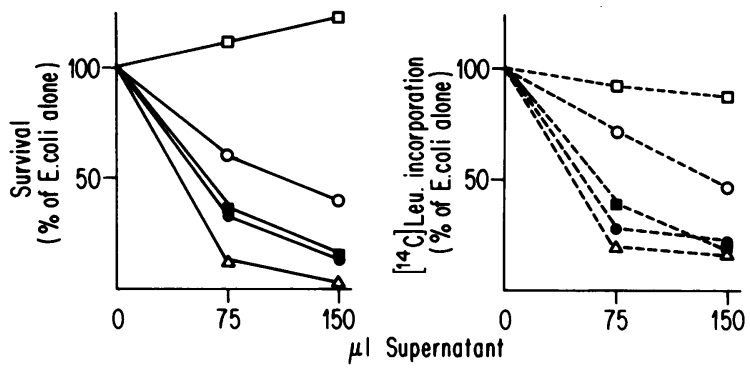

$\Delta$ Protein olone

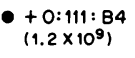

- + J5 (+ galactose) $+J 5(-$ golactose)
O $\left(6 \times 10^{8}\right)$ ( $\left(1.2 \times 10^{9}\right)$

FIGURE 8 Binding of human PMN bactericidal/PI protein to $E$. coli: influence of LPS structure. Supernatant fractions were obtained as described in Methods after preincubation of $50 \mu \mathrm{g}$ of human PMN protein alone $(\triangle)$, or with $E$. coli 0111 : B4 $\left(1.2 \times 10^{9} ; 9\right)$, or with $E$. coli $\mathrm{J} 5$ grown with galactose $\left(1.2 \times 19^{9}, \square\right)$, or without galactose $\left(6 \times 10^{8}, \bigcirc ; 1.2 \times 10^{9}, \square\right)$. These fractions were assayed for bactericidal and PI activities as described in the legend to Fig. 6. The results represent the mean of two closely similar experiments carried out in duplicate.

B4). Furthermore, the human and rabbit proteins exhibit very similar activity and bind in nearly identical amounts to rough bacteria, whereas the somewhat greater activity of the rabbit protein toward smooth bacteria is matched by its greater apparent binding.

Immunochemical analysis of the supernatant fractions obtained by centrifugation of the preincubation mixtures provides evidence that the loss of bactericidal and permeability increasing activities from the soluble phase is indeed due to binding of the bactericidal proteins to the bacterial pellet and not to inactivation.

TABLE II

Comparison of Binding of Human and Rabbit Bactericidal/PI Proteins to Various Strains of Gram-negative Bacteria

\begin{tabular}{lcc}
\hline \multicolumn{1}{c}{ Bacterial strain } & Human & Rabbit \\
\hline & $\begin{array}{c}\mu g \text { protein bound } / 5 \times 10^{7} \\
\text { bacteria }\end{array}$ \\
Rough & & \\
S. typhimurium 395-R10 & $2.8-3.4$ & $3.0-3.3$ \\
S. typhimurium G-30 (-galactose) & $2.7-3.1$ & $2.5-2.9$ \\
E. coli J5 (-galactose) & $2.6-3.4$ & $\mathrm{NT}^{*}$ \\
Smooth & $0.2-0.5$ & $0.6-0.9$ \\
S. typhimurium 395-MS & $0.4-0.6$ & $0.8-1.1$ \\
S. typhimurium G-30 (+galactose) & $0.3-0.5$ & $\mathrm{NT}^{*}$ \\
E. coli 0111:B4 & $0.3-0.7$ & $\mathrm{NT}^{*}$ \\
E. coli J5 (+galactose) & & \\
\hline
\end{tabular}

Protein binding was calculated as described in Methods, using the data shown in Figs. 5-7. Results shown are from two or more experiments and represent the minimum and maximum values obtained.

* Not tested. 
In this experiment we made use of our previous observation $(3,4)$ showing that addition of $\mathrm{Mg}^{2+}\left(\mathrm{or} \mathrm{Ca}^{2+}\right)$ to suspensions of sensitive bacteria exposed to human or rabbit PMN protein initiates repair of the permeability barrier and other envelope alterations.

After incubation of the human protein with $E$. coli J5 (grown without galactose), no bactericidal/PI protein is evident, immunochemically, in the supernatant fraction (Fig. 2). However, after resuspension and incubation of the bacterial pellet in Tris-buffered saline plus $40 \mathrm{mM} \mathrm{MgCl}_{2}$, the supernatant fraction II (see Methods and Fig. 2), obtained after centrifugation, produces an immunoprecipitation reaction with rabbit antiserum against human bactericidal/PI protein. The density of this immunoprecipitate, compared with that of precipitates generated by known amounts of human PMN protein in control wells, is consistent with release from the bacteria of $>50 \%$ of the protein initially added to the bacterial suspension (Fig. 9). Sodium dodecyl sulfate-polyacrylamide gel electrophoresis of supernatant II fraction reveals one major protein component that migrates exactly like the bactericidal/PI protein (not shown). Similar analysis of supernatant fractions I and II obtained from bacterial suspensions incubated without protein shows no re-

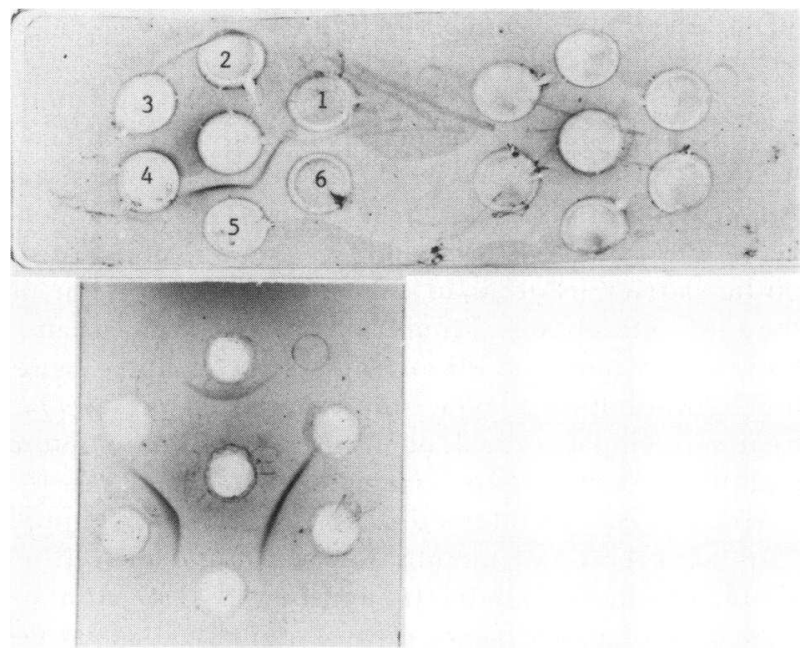

FIGURE 9 Immunochemical evidence of binding of human P.MN bactericidal/PI protein to $E$. coli J5. Supernatant fractions I and II, obtained as described in Methods and Fig. 2, were removed from bacterial suspensions after preincubation with (top left) or without (top right) $50 \mu \mathrm{g}$ of human PMN protein and were assayed by double immunodiffusion (25). Aliquots of 20,40 and $60 \mu \mathrm{l}$ of supernatant fractions I and II were added to peripheral wells numbered 1, 2, and 3 and wells 4,5 , and 6 , respectively. Aliquots $(20,40$, and $60 \mu \mathrm{l})$ of a supernatant fraction derived from $50 \mu \mathrm{g}$ protein preincubated in $0.75 \mathrm{ml}$ saline containing $40 \mathrm{mM} \mathrm{MgCl}_{2}$ were added to peripheral wells 2, 4 and 6, respectively (lower left). Rabbit antiserum against human bactericidal/PI protein was added to each center well. lease of such material as assessed by immunoreactivity or by gel electrophoresis.

\section{DISCUSSION}

Numerous studies have shown that the surface properties of smooth gram-negative bacterial strains provide more protection against antibiotics and the host's humoral and cellular defenses than do those of rough bacteria $(6,7,14-18)$. Although experiments with $S$. typhimurium and $E$. coli strains differing in the polysaccharide chain length of the outer membrane LPS have suggested that LPS structure is a major determinant of gram-negative bacterial virulence (6), it has so far not become clear what the basis is for this apparent relationship. In this study we have shown that bacterial sensitivity or resistance to the effects of purified bactericidal proteins from human and rabbit P.MN on viability and envelope permeability is a function of the binding properties of the outer membrane that vary with the length of the polysaccharide chain of the LPS.

Our previous observations, showing that the bactericidal/PI protein is removed from the medium during incubation with sensitive $E$. coli but can be fully recovered from the medium when incubated with resistant microorganisms such as Serratia marcescens or Staphylococcus aureus (5; unpublished observations), strongly suggested that binding to the microbial envelope is an absolute requisite for expression of the antibacterial activities of these proteins. Although these earlier studies did not reveal which of the many envelope constituents determined whether or not binding takes place, several findings focused our attention on the surface layers of the gram-negative envelope: $(a)$ all of the microbial species tested lacking the gram-negative bacterial outer membrane (including several gram-positive bacterial species and two strains of the fungus Candida) show no sensitivity to high concentrations of the bactericidal/PI proteins $(1,2)$, and $(b)$ sensitive gram-negative bacteria exposed to bactericidal concentrations of the bactericidal/PI proteins exhibit almost unimpaired macromolecular synthesis and $\mathrm{K}^{+}$transport (1-3; unpublished observations), indicating that the structure and function of the cytoplasmic membrane remain singularly unaffected. In contrast, the two envelope alterations that accompany the bactericidal action of the purified leukocyte proteins appear to be confined to the outer membrane, namely, the breakdown of the normal permeability barrier in the outer membrane to ActD (23, 28) and the activation of bacterial phospholipidsplitting activity that resides predominantly in the outer membrane (29-31). That the bactericidal/PI proteins bind to sites on or near the surface is further suggested by the reversal of these envelope effects, 
either by addition of $\mathrm{Mg}^{2+}\left(\right.$ or $\left.\mathrm{Ca}^{2+}\right)$ with concomitant release of bound leukocyte protein (Fig. 9) (but not of appreciable bacterial protein) or by trypsin treatment (unpublished observations) that only destroys protein at the bacterial surface (32). Binding to surface sites, the relatively large size of the bactericidal human and rabbit leukocyte proteins $\left(M_{\mathrm{r}} 60,000\right.$ and 50,000, respectively), and the apparently discrete lesions produced, all together presumably prevent these proteins from traversing beyond the outer membrane.

A common feature of the antimicrobial proteins of PMN is their positive charge (33-35). Polyanions, such as LPS and heparin, complex and inactivate these cationic proteins, and it has been proposed in the past that their action follows binding to negative charges in or on the envelope $(5,33,34)$. At the surface of the gram-negative envelope the LPS are the most dominant negatively charged components (36). Current views of the molecular organization of the outer membrane hold that the phospholipids make up the inner leaflet of the hydrophobic bilayer and the LPS the outer leaflet (12). According to this concept, most or all LPS molecules in the outer membrane turn their negative charges toward the exterior environment and thus become available for interaction with opposing charges. However, the negative charges of the LPS (36) are located near the base of the polysaccharide chain, where this is attached to the lipid A moiety embedded in the bilayer $(12,36)$. Consequently, as the polysaccharide chain lengthens, the negative charges are more buried, and charge interaction with molecules in the environment may become hindered. It is in this light that we interpret our results of experiments with E. coli and S. typhimurium strains as differing in the polysaccharide chain length of their LPS (Fig. 10). We propose that approximately the same number of bactericidal protein molecules produce their effects on viability and permeability of rough and smooth strains of E. coli and S. typhimurium. However, because the apparent binding affinity of the bactericidal proteins varies with the polysaccharide chain length of the LPS, these effects are elicited at different protein concentrations. The number of sites per bacterium, estimated by the maximal amount of bound protein and its molecular weight $(1,2)$, is roughly $5 \times 10^{5}$. The number of LPS molecules per $E$. coli, regardless of polysaccharide chain length, has been calculated to be $\sim 2.5$ $\times 10^{6}(12)$. Thus, saturation of binding sites would correspond statistically to one bactericidal protein molecule bound per five LPS molecules. More precise determination of the binding properties of different bacterial strains with respect to these bactericidal proteins must await their successful radiolabeling.

How these apparently noncatalytic proteins affect the bacterial envelope and multiplication by interacting with the surface layer is not clear. The studies

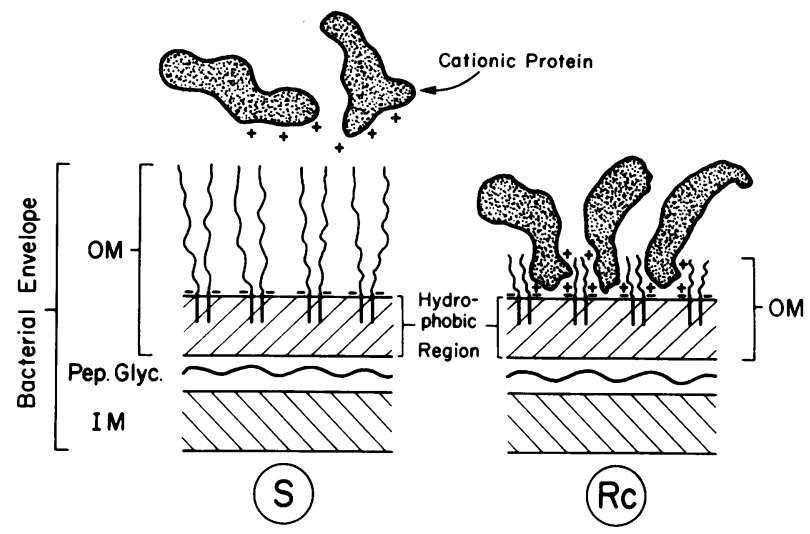

Figure 10 Model describing relationship between LPSsaccharide chain length and action of bactericidal/PI protein on gram-negative bacteria. The gram-negative bacterial envelope consists of three distinct layers $(28,36)$ : the cytoplasmic or inner membrane (IM), the peptidoglycan (Pep. Glyc.) layer, and the outer membrane (OM). The LPS of the outer membrane mainly account for the net negative charge typical of intact gram-negative bacteria. In the envelopes of $S$. typhimurium and E. coli with short-chain saccharide-LPS (Rc), these negative charges are sufficiently exposed to allow ready interaction with the positively charged bactericidal proteins. The longer the polysaccharide chains of the LPS, the more the negative charges are shielded, thereby reducing the likelihood of charge-charge interaction (S). However, at higher ambient concentrations of bactericidal proteins, binding does occur and, when reaching saturation (5), the effects on viability and permeability are the same as on rough strains.

of Nikaido (13) and Leive (28) suggest that exogenous hydrophobic substances, such as ActD, cannot permeate the intact outer membrane because of a hydrophilic barrier external to the hydrophobic region of the outer membrane. Prompt passage of ActD occurs, however, when conditions are created that expose the hydrophobic bilayer: for example, when EDTA treatment chelates divalent cations cross-linking outer membrane components (36).

Apparently, the interaction of the bactericidal proteins with the outer membrane also generates hydrophobic channels allowing penetration of ActD. Attachment of the cationic bactericidal protein to the negative surface charges may produce such an effect through conformational changes in outer membrane components. It is also possible that the tightly membranebound bactericidal leukocyte proteins $(1,5)$ possess hydrophobic domains that, after the initial ionic interaction of protein and bacterium, insert themselves into the hydrophobic bilayer acting as detergents.

As shown in this and previous studies in our laboratory, the remarkable similarity of the biological properties of the human and rabbit PMN bactericidal/PI proteins $(1,2)$ is matched by the close resemblance of their molecular characteristics, including their molecular 
weight, amino acid composition, net charge, and thermal sensitivity $(1,2)$. In addition, the rabbit PMN protein shows cross-immunoreactivity with antiserum generated against the human PMN protein (unpublished observations). It further appears that the role of these proteins in the cell, derived from the human and from the rabbit, is also similar. Thus, the effects of intact human and rabbit PMN, whole PMN homogenates, and progressively purified PMN fractions, on viability and permeability of rough gram-negative bacterial strains, are essentially the same as of the isolated bactericidal/PI protein $(1,2,5,24)$. Other P.MN fractions obtained during purification of the bactericidal/PI protein, however, are devoid of these activities. Such findings suggest that the bactericidal/PI protein is the principal, $\mathrm{O}_{2}$-independent antibacterial agent directed at these gram-negative bacteria.

\section{ACKNOWLEDGMENT}

This work was supported by grant AM 05417 from the U. S. Public Health Services.

\section{REFERENCES}

1. Weiss, J., P. Elsbach, I. Olsson, and H. Odeberg. 1978. Purification and characterization of a potent bactericidal and membrane active protein from the granules of human polymorphonuclear leukocytes. J. Biol. Chem. 253: 26642672.

2. Elsbach, P., J. Weiss, R. C. Franson, S. BeckerditeQuagliata, A. Schneider, and L. Harris. 1979. Separation and purification of a potent bactericidal/permeabilityincreasing protein and a closely associated phospholipase $\mathrm{A}_{2}$ from rabbit polymorphonuclear leukocytes. Observations on their relationship. J. Biol. Chem. 254: 1100011009.

3. Weiss, J., K. Schmeidler, S. Beckerdite-Quagliata, R. Franson, and P. Elsbach. 1976. Reversible envelope effects during and after killing by a highly purified granulocyte preparation. Biochim. Biophys. Acta. 436: 154- 169.

4. Weiss, J., and P. Elsbach. 1977. The use of a phospholipase A-less Escherichia coli mutant to establish the action of granulocyte phospholipase A on bacterial phospholipids during killing by a highly purified granulocyte fraction. Biochim. Biophys. Acta. 466: 23-33.

5. Weiss, J., R. Franson, S. Beckerdite, K. Schmeidler, and P. Elsbach. 1975. Partial characterization and purification of a rabbit granulocyte factor that increases permeability of Escherichia coli. J. Clin. Invest. 55: 33-42.

6. Medearis, D. N., B. M. Camitta, and E. C. Heath. 1968. Cell wall composition and virulence in Escherichia coli. J. Exp. Med. 128: 399-414.

7. Stendahl, O., and L. Edebo. 1972. Phagocytosis of mutants of Salmonella typhimurium by rabbit polymorphonuclear cells. Acta Pathol. Microbiol. Scand. Sect. B Microbiol. Immunol. 80: 481-488.

8. Van Oss, C. J., and C. F. Gillman. 1972. Phagocytosis as a surface phenomenon. I. Contact angles and phagocytosis of non-opsonized bacteria. J. Reticuloendothel. Soc. 12: 283-292.

9. Cunningham, R. K., T. O. Söderström, C. F. Gillman, and C. J. van Oss. 1975. Phagocytosis as a surface phenomenon. Contact angles and phagocytosis of rough and smooth strains of Salmonella typhimurium and the influence of specific antiserum. Immunol. Commun. 4: 429-442.

10. Sanderson, K. E., T. MacAlister, J. W. Costerton, and K-J. Cheng. 1974. Permeabiltiy of lipopolysaccharide-deficient (rough) mutants of Salmonella typhimurium to antibiotics, lysozyme and other agents. Can.J. Microbiol. 20: $1135-1145$.

11. Magnusson, K. E., O. Stendahl, C. Tagesson, L. Edebo, and G. Johanssen. 1977. The tendency of smooth and rough Salmonella typhimurium bacteria and lipopolysaccharide to hydrophobic and ionic interaction, as studied in aqueous polymer two-phase systems. Acta Pathol. Microbiol. Scand. Sect. B Microbiol. Immunol. 85: $212-218$.

12. Smit, J., Y. Kamio, and H. Nikaido. 1975. Outer membrane of Salmonella typhimurium: chemical analysis and freezefracture studies with lipopolysaccharide mutants. $J$. Bacteriol. 124: 942-958.

13. Nikaido, H. 1976. Outer membrane of Salmonella typhimurium: transmembrane diffusion of some hydrophobic substances. Biochim. Biophys. Acta. 433: 118132.

14. Friedberg, D., I. Friedberg, and M. Shilo. 1970. Interaction of gram-negative bacteria with the lysosomal fraction of polymorphonuclear leukocytes. II. Changes in the cell envelope of Escherichia coli. Infect. Immun. 1: 311-318.

15. Tagesson, C., and O. Stendahl. 1973. Influence of cell surface lipopolysaccharide structure of Salmonella typhimurium on resistance to intracellular bactericidal systems.Acta Pathol.Microbiol. Scand. Sect. B.Microbiol. Immuno. 81: 473-481.

16. Rest, R. F., M. H. Cooney, and J. K. Spitznagel. 1978. Bactericidal activity of specific and azurophil granules from human neutrophils: studies with outer membrane mutants of Salmonella typhimurium LT-2. Infect. Immun. 19: $131-137$.

17. Modrzakowski, M. C., M. H. Cooney, L. E. Martin, and J. K. Spitznagel. 1979. Bactericidal activity of fractionated granule contents from human polymorphonuclear leukocytes. Infect. Immun. 23: 587-591.

18. Reynolds, B. L., and H. Pruul. 1971. Protective role of smooth lipopolysaccharide in the serum bactericidal reaction. Infect. Immun. 4: 753-771.

19. Holme, T., A. A. Lindberg, P. J. Garegg, and T. Onn. 1968. Chemical composition of cell wall polysaccharide in rough mutants of Salmonella typhimurium. J. Gen. Microbiol. 52: 45-54.

20. Osborn, M. J., S. M. Rosen, L. Rothfield, and B. L. Horecker. 1962. Biosynthesis of bacterial lipopolysaccharide. I. Envelope incorporation of galactose in a mutant strain of Salmonella. Proc. Natl. Acad. Sci. U.S.A. 48: $1831-1838$.

21. Elbein, A. D., and E. C. Heath. 1965. The biosynthesis of cell wall lipopolysaccharide in Escherichia coli. J. Biol. Chem. 240: 1919-1925.

22. Simon, E. J., and D. Van Praag. 1964. Inhibition of RNA synthesis in Escherichia coli by levorphanol. Proc. Natl. Acad. Sci. U.S.A. 51: 877-883.

23. Hurwitz, J., J. J. Furth, M. Malamy, and M. Alexander. 1962. The role of DNA in RNA synthesis. III. The inhibition of the enzymatic synthesis of RNA and DNA by actinomycin and proflavin. Proc. Natl. Acad. Sci. U.S.A. 48: $1222-1230$.

24. Beckerdite, S., C. Mooney, J. Weiss, R. Franson, K. 
Schmeidler and P. Elsbach. 1974. Early and discrete changes in permeability of Escherichia coli and certain other gram-negative microorganisms during killing by granulocytes. J. Exp. Med. 140: 396-409.

25. Ouchterlony, O. 1949. Antigen-antibody reactions in gels. Acta Pathol. Microbiol. Scand. 26: 507-515.

26. Schnaitman, C. A. 1974. Outer membrane proteins of Escherichia coli. IV. Difference in outer membrane protein due to strain and cultural differences. J. Bacteriol. 118: 454-464.

27. Osborn, M. J., J. E. Gander, E. Parisi, and J. Carson. 1972. Mechanism of assembly of the outer membrane of Salmonella typhimurium. Isolation and characterization of cytoplasmic and outer membrane. J. Biol. Chem. 247: 3962-3972.

28. Leive, L. 1974. The barrier function of the gram-negative bacterial envelope. Ann. N. Y. Acad. Sci. 235: 109-129.

29. Bell, R. .M., R. D. Mavis, M. J. Osborn, and P. R. Vagelos. 1971. Enzymes of phospholipid metabolism: localization in the cytoplasmic and outer membrane of the cell envelope of Escherichia coli and Salmonella typhimurium. Biochim. Biophys. Acta. 249: 628-635.

30. White, D. A., F. R. Albright, W. J. Lennarz, and C. A. Schnaitman. 1971. Distribution of phospholipid-synthesizing enzymes in the wall and membrane sub- fractions of the envelope of Escherichia coli. Biochim. Biophys. Acta. 249: 636-647.

31. Vos, M. M., J. A. F. Op den Kamp, S. BeckerditeQuagliata, and P. Elsbach. 1978. Acylation of monoacylglycerophosphoethanolamine in the inner and outer membrane of the envelope of an Escherichia coli K12 strain and its phospholipase A-deficient mutant. Biochim. Biophys. Acta. 508: 165-173.

32. Maede, A., and M. Nomura. 1966. Interaction of colicins with bacterial cells. I. Studies with radioactive colicins. J. Bacteriol. 91: 685-694.

33. Hirsch, J. G. 1960. Further studies on preparation and properties of phagocytin. J. Exp. Med. 111: 323-337.

34. Zeya, H. I., and J. K. Spitznagel. 1966. Cationic proteins of polymorphonuclear leukocyte lysosomes. II. Composition, properties and mechanism of antibacterial action. J. Bacteriol. 91: 755-762.

35. Odeberg, H., I. Olsson, and P. Venge. 1975. Cationic proteins of human granulocytes. J. Clin. Invest. 56: $1118-1124$.

36. Ghuysen, J. M. 1977. Biosynthesis and assembly of bacterial cell walls. In The Synthesis, Assembly and Turnover of Cell Surface Components. G. Poste and G. L. Nicolson, editors. Elsevier/North-Holland, Biomedical Press., New York. IV: 463-595. 